Pilot To Promote Entry of Structured Data Into the Systematic Review Data Repository (SRDR) 


\section{Pilot To Promote Entry of Structured Data Into the Systematic Review Data Repository}

Prepared for:

Agency for Healthcare Research and Quality

U.S. Department of Health and Human Services

5600 Fishers Lane

Rockville, MD 20857

www.ahrq.gov

Contract No. 290-2015-00002-I; 290-2015-00006-I

Prepared by:

Brown Evidence-based Practice Center

Providence, RI

Johns Hopkins University Evidence-based Practice Center

Baltimore, MD

Investigators:

Ian J. Saldanha, M.B.B.S., M.P.H., Ph.D.

Birol Senturk, B.S.

Bryant T. Smith, M.P.H.

Karen A. Robinson, M.Sc., Ph.D.

AHRQ Publication No. 19-EH028-EF

October 2019 


\section{Key Messages}

\section{Purpose of Project}

To promote the entry of structured data into the Systematic Review Data Repository (SRDR) to facilitate interoperability and use of systematic review data by end-users.

\section{Key Messages}

- Using an online survey of nine Project Leads we determined that Microsoft Excel and DistillerSR were the primary sources of flat file data that were recently submitted by Evidence-based Practice Centers (EPCs) to SRDR.

- We refined and pilot tested an approach for importing MS Excel files into SRDR.

- We developed and pilot tested an approach to import files from DistillerSR into SRDR.

- We developed detailed step-by-step instructions for both approaches. 
This report is based on research conducted by the Johns Hopkins University and Brown Evidence-based Practice Centers (EPC) under contract to the Agency for Healthcare Research and Quality (AHRQ), Rockville, MD (Contract Nos. 290-2015-00002-I and 290-2015-00006-I). The findings and conclusions in this document are those of the authors, who are responsible for its contents; the findings and conclusions do not necessarily represent the views of AHRQ. Therefore, no statement in this report should be construed as an official position of AHRQ or of the U.S. Department of Health and Human Services.

\section{None of the investigators have any affiliations or financial involvement that conflicts with the material presented in this report.}

The information in this report is intended to help healthcare decision makers—patients and clinicians, health system leaders, and policymakers, among others—make well-informed decisions and thereby improve the quality of healthcare services. This report is not intended to be a substitute for the application of clinical judgment. Anyone who makes decisions concerning the provision of clinical care should consider this report in the same way as any medical reference and in conjunction with all other pertinent information, i.e., in the context of available resources and circumstances presented by individual patients.

This report is made available to the public under the terms of a licensing agreement between the author and the Agency for Healthcare Research and Quality. This report may be used and reprinted without permission except those copyrighted materials that are clearly noted in the report. Further reproduction of those copyrighted materials is prohibited without the express permission of copyright holders.

AHRQ or U.S. Department of Health and Human Services endorsement of any derivative products that may be developed from this report, such as clinical practice guidelines, other quality enhancement tools, or reimbursement or coverage policies may not be stated or implied.

Persons using assistive technology may not be able to fully access information in this report. For assistance contact EPC@ahrq.hhs.gov.

Suggested citation: Saldanha IJ, Senturk B, Smith BT, Robinson, KA. Pilot to Promote Entry of Structured Data Into the Systematic Review Data Repository. Methods Research Report. (Prepared by the Brown University and Johns Hopkins University Evidence-based Practice Centers under Contract Nos. 290-2015-00002-I and 290-2015-00006-I.) AHRQ Publication No.19-EH028-EF. Rockville, MD: Agency for Healthcare Research and Quality; October 2019. Posted final reports are located on the Effective Health Care Program search page.

DOI: https://doi.org/10.23970/AHRQEPCMETHQUALIMPRSRDR. 


\section{Preface}

The Agency for Healthcare Research and Quality (AHRQ), through its Evidence-based Practice Centers (EPCs), sponsors the development of evidence reports and technology assessments to assist public- and private-sector organizations in their efforts to improve the quality of healthcare in the United States. The reports and assessments provide organizations with comprehensive, science-based information on common, costly medical conditions and new healthcare technologies and strategies. The EPCs systematically review the relevant scientific literature on topics assigned to them by AHRQ and conduct additional analyses when appropriate prior to developing their reports and assessments.

To improve the scientific rigor of these evidence reports, AHRQ supports empiric research by the EPCs to help understand or improve complex methodologic issues in systematic reviews. These methods research projects are intended to contribute to the research base in and be used to improve the science of systematic reviews. They are not intended to be guidance to the EPC program, although may be considered by EPCs along with other scientific research when determining EPC program methods guidance.

AHRQ expects that the EPC evidence reports and technology assessments will inform individual health plans, providers, and purchasers as well as the healthcare system as a whole by providing important information to help improve healthcare quality. The reports undergo peer review prior to their release as a final report.

If you have comments on this Methods Research Project they may be sent by mail to the Task Order Officer named below at: Agency for Healthcare Research and Quality, 5600 Fishers Lane, Rockville, MD 20857, or by email to epc@ahrq.hhs.gov.

Gopal Khanna, M.B.A.

Director

Agency for Healthcare Research and Quality

Stephanie Chang, M.D., M.P.H.

Director

Evidence-based Practice Center Program

Center for Evidence and Practice Improvement Agency for Healthcare Research and Quality
Arlene Bierman, M.D., M.S.

Director

Center for Evidence and Practice Improvement

Agency for Healthcare Research and Quality

Lionel L. Bañez, M.D.

Task Order Officer

Center for Evidence and Practice

Improvement

Agency for Healthcare Research and Quality 


\section{Pilot To Promote Entry of Structured Data Into the Systematic Review Data Repository (SRDR)}

\section{Structured Abstract}

Background. The Systematic Review Data Repository (SRDR) was launched in 2012 as a collaborative, Web-based platform for extracting data from studies included in systematic reviews. The vision was to create a free, open-access repository of extracted data which could reduce unnecessary duplication of effort and facilitate the efficient production of systematic reviews.

Objective. To promote the entry of structured data into SRDR to promote interoperability and use of systematic review data by end-users.

Methods. We completed two steps. First, we determined the sources of flat file data that were recently submitted by Evidence-based Practice Centers (EPCs) to SRDR. We conducted a survey of EPC Project Leads that had recently uploaded to SRDR data from a systematic review in a flat file. Second, we determined and pilot tested approaches for importing structured systematic review data.

Results. The survey was completed by nine of nine eligible EPC Project Leads (100\%). In addition to information about usability of SRDR, the primary result was that MS Excel, MS Word and DistillerSR were the most used tools for extracting data and creating tables. An approach for importing MS Excel files into SRDR was refined and pilot tested. An approach was also developed and pilot tested to import files from DistillerSR into SRDR. Detailed instructions, with screenshots, were developed for both approaches.

Conclusions: Improving the ability to search for and produce reviews that are interoperable for users requires production and storage of systematic review data in a structured format. The results from this work will promote interoperability and use of systematic data in SRDR. 


\section{Contents}

Background ........................................................................................................................................... 1

Methods................................................................................................................................................ 2

Aim 1: Determine the Sources of Flat File Data That Were Recently Submitted by EPCs to

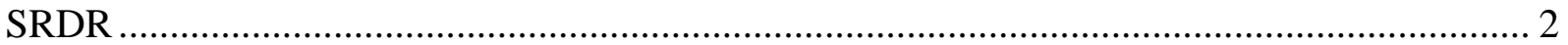

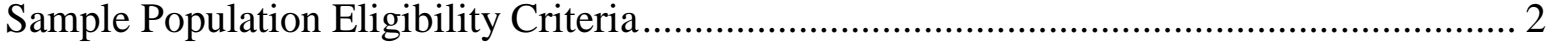

Contact with Eligible Population ................................................................................... 2

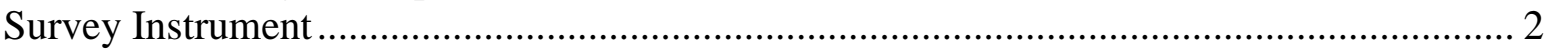

Aim 2: Determine and Pilot an Approach for Importing Structured Data from Sources of Flat

File Systematic Review Data.................................................................................................. 3

Importing Data from MS Excel ...................................................................................... 3

Importing Data from DistillerSR ................................................................................. 3

Results ..................................................................................................................................................... 4

Aim 1: Determine the Sources of Flat File Data that were Recently Submitted by EPCs to

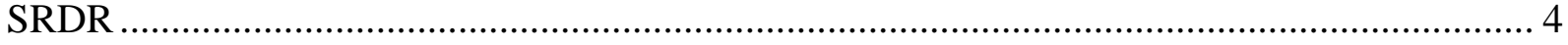

Survey Results ........................................................................................................... 4

Aim 2: Determine and Pilot an Approach for Importing Structured Data from Sources of Flat

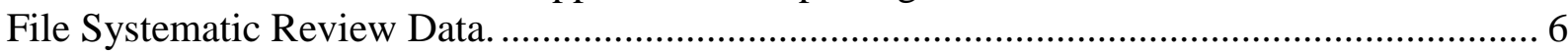

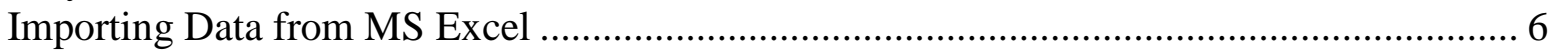

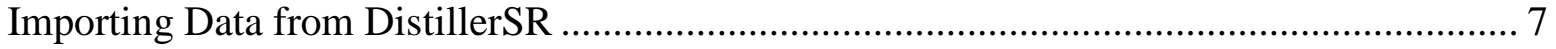

Discussion..................................................................................................................................................... 9

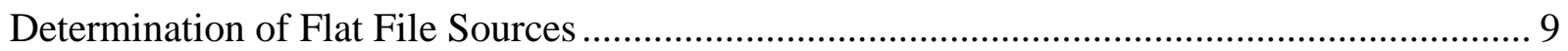

Limitation to Survey .................................................................................................... 9

Importing Data from Flat File Sources .................................................................................. 9

Time and Effort for Implementation................................................................................... 9

Data Rights, Section 508 Compliance, and Interoperability...................................................... 9

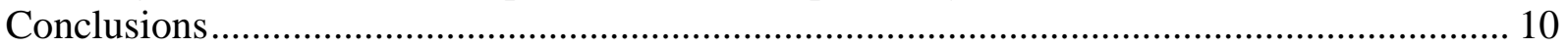

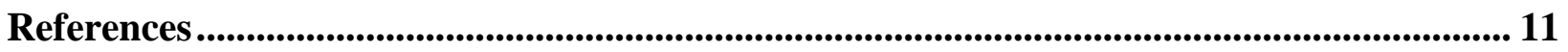

Tables

Table 1. Software tools/programs that were primarily used for extracting and managing data for the reviews ............................................................................................................................. 4

Table 2. Specific features/aspects that motivated the choice of software tools/programs that were primarily used for extracting data for the reviews ......................................................................... 5

Table 3. Why SRDR was not used during the systematic reviews ............................................... 6

\section{Figures}

Figure 1. Aim 1: Disposition of eligible systematic reviews, EPC Project Leads, and EPCs for the survey 


\section{Appendixes}

Appendix A. Survey Instrument Administered Through Qualtrics

Appendix B. Screenshot of the MS Excel File Template for Importing Data Into the SRDR Design Tab

Appendix C. Screenshot of the MS Excel File Template for Importing Data Into the SRDR Outcomes Tab

Appendix D. Instructions for Importing Structured Data from DistillerSR into SRDR 


\section{Background}

In 2012, the Brown University Evidence-based Practice Center (EPC) launched the Systematic Review Data Repository (SRDR), ${ }^{1}$ which, in 2018, was updated to SRDR+. The vision behind SRDR was for it to serve two purposes: (1) a collaborative, Web-based platform for extracting data from studies included in systematic reviews, and (2) a free, open-access repository of extracted data. For the Agency for Healthcare Research and Quality (AHRQ) EPC Program, such a repository could reduce unnecessary duplication of effort (i.e., re-identification, re-extraction of data) and facilitate the efficient production of systematic reviews.

In 2015, AHRQ mandated that EPCs submit extracted data to SRDR upon completion of each evidence report. However, as of February 26, 2019, of the 89 EPC evidence reviews with data submitted to the SRDR website (https://srdr.ahrq.gov/projects/published), 46 reviews (52\%) have submitted data to SRDR retrospectively only as unstructured data (using flat files, e.g., Microsoft ${ }^{\circledR}$ [MS] Excel files, Adobe ${ }^{\circledR}$ Portable Document Format [PDF] files). While submitting unstructured data satisfies the mandate to "submit review data to SRDR," it does not help us attain the vision of SRDR as a shared resource.

The current project was a partnership between the Johns Hopkins University and Brown University EPCs. The overall objective of this project was to conduct work to promote the entry of structured data into SRDR to promote interoperability and use of systematic review data by end-users. With this objective in mind, we had two Aims for this project:

- $\quad$ Aim 1: Determine the sources of flat file data that were recently submitted by EPCs to SRDR; and

- $\quad$ Aim 2: Determine and pilot an approach for importing structured data from sources of flat file systematic review data. 


\section{Methods}

The overall methods for this project were to conduct a survey of Project Leads of recent EPC evidence reports for which data were uploaded only as flat files to identify the sources of the flat file data, and then to determine and pilot an approach for importing structured data from popular sources.

\section{Aim 1: Determine the Sources of Flat File Data That Were Recently Submitted by EPCs to SRDR}

\section{Sample Population Eligibility Criteria}

We considered as eligible for Aim 1 all individuals who were listed as EPC Project Leads (typically the Project Managers) in the SRDR record for projects (i.e., evidence reviews) that fulfilled each of the following four criteria:

- Conducted by a current EPC and funded by AHRQ;

- Pertained to a full systematic review (e.g., not a Technical Brief);

- Review data were made publicly available on SRDR in 2016, 2017, or 2018; and

- Review data were submitted to SRDR retrospectively only as unstructured data using flat files (i.e., using SRDR's “Upload” functionality only or using SRDR's “Upload” and "Import" functionalities only to import files).

Where more than one review with the same EPC Project Lead was eligible, we considered as eligible only the most recent review. We restricted the sample size to nine respondents.

\section{Contact With Eligible Population}

On February 12, 2019, the Lead of the current project (KAR) sent an email to all eligible survey participants and, when the participant was not the current Director of the relevant EPC, also copied the current Director on the email. The email contained a brief description of the purpose of the current project and a Weblink to the survey instrument. The email provided information about the specific systematic review regarding which we wanted the participant to provide responses. Participants were also informed that completing the survey would take no more than 5 minutes of their time and that results would be non-identifiable and provided only in aggregate. Two weeks after the initial email, we sent a reminder email to those eligible participants who had not yet completed the survey.

\section{Survey Instrument}

Appendix A provides the survey that we implemented using Qualtrics ${ }^{\circledR}$ (Provo, Utah, USA). We asked participants for their name (to confirm accurate mapping to the appropriate review). We informed each participant that their responses, their EPC's name, and the systematic review to which their responses pertained would be kept confidential. The survey included four main items: (1) the software tool or program that was used for extracting data for the review; (2) specific features/aspects that motivated the choice of the software tool or program named in (1); (3) the software tool or program that was used for managing extracted data for the review; and (4) reasons for not using $S R D R$ for the review. 


\section{Aim 2: Determine and Pilot an Approach for Importing Structured Data from Sources of Flat File Systematic Review Data.}

We focused on piloting approaches to importing structured data from MS Excel (Microsoft ${ }^{\circledR}$, Redmond, Washington, USA) and DistillerSR (Evidence Partners ${ }^{\circledR}$, Ottawa, Canada) as these were the most frequently used flat file sources by the survey respondents.

\section{Importing Data From MS Excel}

We developed, fine-tuned and pilot tested a process for importing structured data from MS Excel into SRDR.

\section{Importing Data From DistillerSR}

We worked with Evidence Partners ${ }^{\circledR}$, the developers of DistillerSR, to promote two-way interoperability between SRDR and DistillerSR. Such interoperability did not exist prior to this project. The goals of such interoperability are to enable users to export extracted data from one software application to the other.

To develop and pilot test the approach to import data from DistillerSR into SRDR, we used an ongoing JHU EPC systematic review - Antipsychotics for the Prevention and Treatment of Delirium (protocol available at https://effectivehealthcare.ahrq.gov/topics/antipsychotics/research-protocol). In this project, JHU extracted data using forms in DistillerSR and then created MS Excel files. 


\section{Results}

\section{Aim 1: Determine the Sources of Flat File Data That Were Recently Submitted by EPCs to SRDR}

\section{Survey Results}

Figure 1 displays the disposition of eligible systematic reviews, EPC Project Leads, and EPCs for the survey. There were 23 systematic reviews potentially eligible (from 7 EPCs), from which we excluded 12 systematic reviews because the same EPC Project Lead had more recent reviews that were eligible, 1 systematic review by one of our own EPCs, and 1 systematic review because we needed to restrict the survey to 9 respondents to comply with federal regulations.

Figure 1. Aim 1: Disposition of eligible systematic reviews, EPC Project Leads, and EPCs for the survey

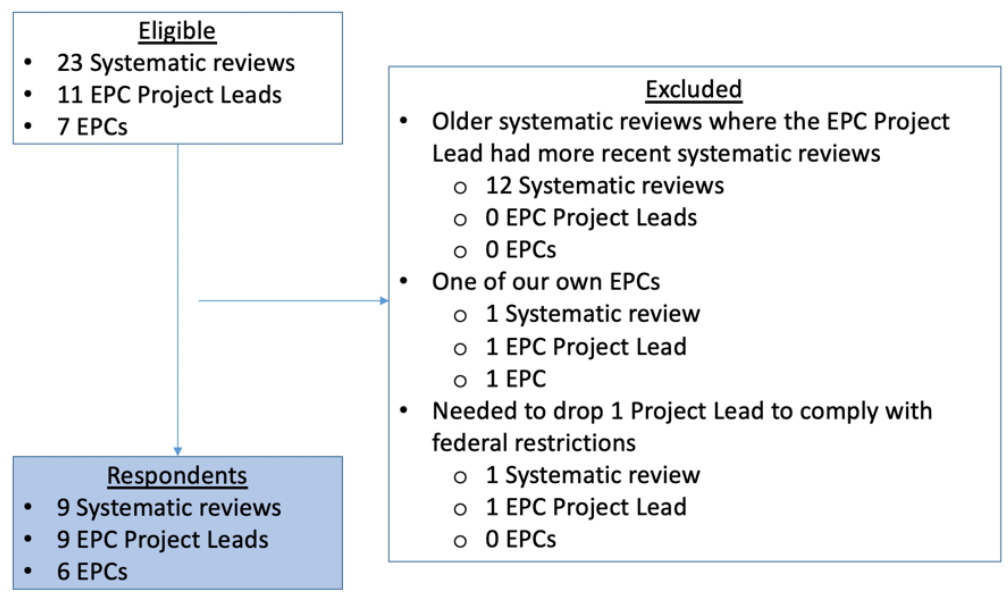

MS Word (Microsoft ${ }^{\circledR}$, Redmond, Washington, USA), MS Excel, and DistillerSR were the only reported software tools/programs used for extracting data, managing data, and producing tables for systematic reviews (Table 1).

Table 1. Software tools/programs that were primarily used for extracting and managing data for the reviews

\begin{tabular}{|c|c|c|}
\hline Use & Software tool/program & $\begin{array}{r}\text { Number (\%) of } \\
\text { respondents }\end{array}$ \\
\hline \multirow[t]{7}{*}{ Extracting Data } & Microsoft Word (Microsoft ${ }^{\circledR}$, Redmond, Washington, USA) & $3(33)$ \\
\hline & Microsoft Excel (Microsoft ${ }^{\circledR}$, Redmond, Washington, USA) & $3(33)$ \\
\hline & DistillerSR (Evidence Partners ${ }^{\circledR}$, Ottawa, Canada) & $3(33)$ \\
\hline & RedCap (Vanderbilt University, Nashville, Tennessee, USA) & - \\
\hline & Covidence (Covidence, Melbourne, Australia) & - \\
\hline & Microsoft Access (Microsoft ${ }^{\circledR}$, Redmond, Washington, USA) & - \\
\hline & Other & - \\
\hline \multirow{7}{*}{$\begin{array}{l}\text { Extracting Data and/or } \\
\text { Producing Tables }\end{array}$} & Microsoft Word (Microsoft ${ }^{\circledR}$, Redmond, Washington, USA) & $4(44)$ \\
\hline & Microsoft Excel (Microsoft ${ }^{\circledR}$, Redmond, Washington, USA) & $3(33)$ \\
\hline & DistillerSR (Evidence Partners ${ }^{\circledR}$, Ottawa, Canada) & $2(22)$ \\
\hline & RedCap (Vanderbilt University, Nashville, Tennessee, USA) & - \\
\hline & Covidence (Covidence, Melbourne, Australia) & - \\
\hline & Microsoft Access (Microsoft ${ }^{\circledR}$, Redmond, Washington, USA) & - \\
\hline & Other & - \\
\hline
\end{tabular}


Table 2 lists the specific features/aspects that motivated the choices of MS Word, MS Excel, and DistillerSR. Respondents who chose MS Word for data extraction noted its familiarity and ease of use as well as the fact that EPC reports need to be created in MS Word; extracting data directly into MS Word would thus "... remove the step of converting data from another software's output...” into MS Word. Respondents who chose MS Excel for data extraction noted its familiarity, ease of use, and ability to convert the data to MS Word for report writing. In addition, respondents noted the flexibility of MS Excel as being an attractive feature, specifically the ability to edit fields during data extraction and the ability to "hide, sort, and add columns and rows" (presumably during data management). Respondents who chose DistillerSR for data extraction noted user-friendliness and the fact that it is a program that offers the ability to conduct multiple systematic review tasks, such as title and abstract screening, full-text screening, and data extraction (Table 2).

Table 2. Specific features/aspects that motivated the choice of software tools/programs that were primarily used for extracting data for the reviews

\begin{tabular}{|c|c|}
\hline $\begin{array}{l}\text { Software } \\
\text { tool/program }\end{array}$ & $\begin{array}{l}\text { Specific features/aspects that motivated the choice } \\
\text { (Exact quotes) }\end{array}$ \\
\hline Microsoft Word & $\begin{array}{l}\text { We chose to use MS Word for data abstraction because we planned to use it to generate our } \\
\text { report's tables and wanted to remove the step of converting data from another software's } \\
\text { output into something that would fit Word's formatting requirements/limits. } \\
\text { It is what I usually use. } \\
\text { Ease of use }\end{array}$ \\
\hline ft Excel & $\begin{array}{l}\text { Group familiarity with program. Being able to hide, sort, and add columns and rows, being able } \\
\text { to search (and replace) for terms. } \\
\text { Flexibility in selecting, specifying, and reporting outcomes for this especially iterative project. It } \\
\text { naturally takes a while to figure out which questionnaires, harms, etc are reported by the } \\
\text { included studies, so we prefer using a platform that allows us to edit the fields as we go along } \\
\text { (as opposed to having to specify these first, as is necessary for Distiller etc.) } \\
\text { We chose to use Excel for } 3 \text { primary reasons: (1) the ability to convert the data abstraction from } \\
\text { Excel directly into Microsoft Word in table format; (2) the ability to sort/reorganize the data in a } \\
\text { variety of ways as needed; and (3) the ability to easily convert the data into a form that can be } \\
\text { sent to a statistician (we usually do this in Excel as well). }\end{array}$ \\
\hline DistillerSR & $\begin{array}{l}\text { This was a large project and we needed an program that allowed us to do all three major tasks: } \\
\text { screening, full-text screening, and data abstraction. Distiller is the only program that met those } \\
\text { needs. } \\
\text { User friendly, and it's the default software we use at our EPC. }\end{array}$ \\
\hline
\end{tabular}

Table 3 lists the specific reasons why the respondents did not use SRDR during the systematic reviews. The most common reasons were that the learning curve was too steep (7 respondents; 78\%), the question types were not flexible enough (6 respondents; $67 \%$ ), and the format of data exported from SRDR was not useful (5 respondents; 56\%). We will incorporate these insights into the Brown EPC's efforts to improve and further advance SRDR. These insights are not further discussed in this report. 
Table 3. Why SRDR was not used during the systematic reviews

\begin{tabular}{|c|c|c|}
\hline Systematic review step & Reason* & $\begin{array}{r}\text { Number (\%) of } \\
\text { respondents }\end{array}$ \\
\hline \multirow{2}{*}{$\begin{array}{l}\text { Form Development/ } \\
\text { Project Management }\end{array}$} & The question types in SRDR were not flexible enough. & $6(67)$ \\
\hline & The process of citation importing was too cumbersome. & $3(33)$ \\
\hline \multirow{2}{*}{$\begin{array}{l}\text { Data Extraction/ } \\
\text { Adjudication }\end{array}$} & The learning curve for using SRDR was too steep. & $7(78)$ \\
\hline & The data adjudication tool was not available. & $1(11)$ \\
\hline \multirow[t]{2}{*}{ Data Exporting } & The format of data exported from SRDR was not useful. & $5(56)$ \\
\hline & Exporting data was too slow. & $2(22)$ \\
\hline \multirow[t]{6}{*}{ General/Other } & $\begin{array}{l}\text { The available formats and/or processes for importing data } \\
\text { (retrospectively) were too limited. }\end{array}$ & $4(44)$ \\
\hline & Abstract screening was not available in SRDR. & $4(44)$ \\
\hline & The SRDR tool generally ran too slowly. & $2(22)$ \\
\hline & It was unclear how to get support if needed. & $2(22)$ \\
\hline & There were delays in getting support when needed. & $2(22)$ \\
\hline & There were other reasons. & $4(44)$ \\
\hline
\end{tabular}

* Respondents could select more than one reason.

\section{Aim 2: Determine and Pilot an Approach for Importing Structured Data From Sources of Flat File Systematic Review Data.}

\section{Importing Data From MS Excel}

We developed and pilot tested a process that supports the importing of study data (for one or more study records) from MS Excel files into the following tabs of an extraction form in SRDR: Publications, Design, Arms, Arm Details, Baseline, Outcomes, Outcome Details, and Adverse Events. We developed these steps and tested them internally by using MS Excel files from a recent Johns Hopkins EPC project on management of patients with delirium.

Here, we summarize the process that was developed for importing study data from MS Excel files. Currently, data to be imported into tabs on SRDR extraction forms must be saved on separate MS Excel files (one for each tab). The name of the file needs to match exactly with the tab name on SRDR extraction forms.

Careful formatting of each MS Excel file allows SRDR to import the data and populate the appropriate fields (e.g., PubMed ID, Title, Author) in the appropriate tab of an SRDR extraction form. To this end, each MS Excel file must contain specific column headers (with data from each study in the same column) that are sorted (from left to right) in the same way as the data extraction form items are sorted from (from top to bottom) in the SRDR data extraction form.

To guide users through the process of importing data from MS Excel into SRDR, we developed a detailed, step-by-step Tutorial (https://s3.amazonaws.com/srdr/Tutorial_for_using_the_Data_Import_Tool.pdf), Frequently Asked Questions (https://srdr.ahrq.gov/help\#question55), and SRDR extraction form tab-specific MS Excel file templates with the required formatting guidelines incorporated. Appendixes B and $\mathrm{C}$ provide screenshots of the MS Excel file templates for importing data into the Design tab and Outcomes tab, respectively.

The importing of data into the Results and Quality tabs are not yet supported. 


\section{Considerations When Importing Data From MS Excel}

In developing the process for importing data from MS Excel, we identified certain considerations that will need to be made when importing data into SRDR. These considerations would facilitate high levels of accuracy, completeness, and fidelity. The considerations include:

- The questions in the column headings in MS Excel should map exactly to questions (or items) in data extraction forms in SRDR. As such, the MS Excel sheets should be designed so as to enable such mapping.

- For multiple-choice type questions, the text entered into the individual study-specific cells in the MS Excel spreadsheets should be exact matches with the answer options in data extraction forms in SRDR.

- Information that is to be imported into SRDR should be provided only in the visible MS Excel layer (i.e., within the cells) rather than being visible only upon clicking in or hovering over an individual cell. In other words, no special cell formats or cell comments should be used to convey additional information about the cell.

- We have not yet incorporated a mechanism through which SRDR indicates to users when there are unexpected data formats in the uploaded data from MS Excel. For example, when a plain text field is imported into a numeric field, SRDR could create highlight the mismatch in a bright color to help the user find and correct the problem.

\section{Importing Data From DistillerSR}

We summarize in Appendix D the process we have developed for importing structured data from DistillerSR into SRDR. In short, the process involves three steps: (1) exporting a file containing study references from DistillerSR, (2) exporting section file(s) from DistillerSR, and (3) importing the references file and section file(s) into SRDR. We developed these steps and tested them internally by using exported files from a recent Johns Hopkins EPC project on management of patients with delirium. These steps are intended to apply to the end of the process of data extraction in a systematic review, once the data are already extracted in DistillerSR.

At the June 6, 2019 AHRQ In-Person Meeting in Rockville, Maryland, we presented the findings of this project and a demonstration of importing data from MS Excel files, both those arising from DistillerSR exports and de novo, into SRDR. We received positive feedback. In general, attendees at the meeting believed that this process would be very useful for their systematic reviews. Among the suggestions received were that SRDR should also, in the future, allow the importing of various types of outcomes data, and should allow interoperability with other data extraction platforms, such as RevMan.

\section{Limitations to Process of Importing Data From DistillerSR}

One limitation to the process we developed for importing data from DistillerSR is related to differences in how DistillerSR and SRDR collect and store systematic review data. For example, SRDR projects contain structured elements, such as populations, outcomes, and comparisons that have no counterpart in DistillerSR. This incompatibility makes it difficult to create a fully formed SRDR project by interpreting data exports out of DistillerSR. As a compromise, when importing data, SRDR creates a barebones version of the project that contains none of the structured elements, such as outcomes or comparisons. Rather, SRDR imports each DistillerSR file into a separate data extraction form section, where the data contained in the file are 
represented as question-answer pairs. The names of the imported extraction form sections are the choice of the user importing the project.

Another limitation to the process we developed is that once a project is imported, additional DistillerSR files cannot be imported subsequently into the same project. Therefore, we strongly recommend that the user export all the data out of DistillerSR and only then begin the import process into SRDR. 


\section{Discussion}

\section{Determination of Flat File Sources}

For the purpose of the current project, there were two main conclusions that motivate specific avenues for subsequent steps taken in Aim 2.

The survey in Aim 1 revealed that the most frequently-used sources of flat file data being submitted to SRDR from EPCs were MS Word, MS Excel, and DistillerSR. The main reasons why these tools are being used are familiarity, flexibility, and ability to conduct multiple systematic review tasks within the same program.

While the vision behind the development (and advancement) of SRDR was to serve two main purposes (i.e., data extraction and data archival), our purpose in conducting this project was not to change EPCs' preferred choice of tools for data extraction. Instead, we endeavored to improve the ease with which structured data can be imported into SRDR. We have identified two areas in which we can improve SRDR's functionality in this regard - to improve (1) the functionality of importing data from MS Excel into SRDR, and (2) the interoperability of data between DistillerSR and SRDR. We pursued these two areas in Aim 2.

\section{Limitation to Survey}

The small sample size (nine respondents) is an important limitation to the findings of this survey. As such, the survey's findings should not be construed as being reflective of systematic reviewers in general.

\section{Importing Data From Flat File Sources}

We developed approaches for importing data from MS Excel and from DistillerSR into SRDR. The utility of the importing process to EPCs will need to be evaluated in the future. Evaluation of projects uploaded to SRDR will also need to determine if facilitating importing of data into SRDR from these two frequently used programs will limit the publication of flat files on SRDR.

We chose not to develop a process for importing data from MS Word because MS Word is a word-processing tool and is not designed for structured data entry. It does not have spreadsheet capabilities, such as formula-based calculations and sorting data columns. Moreover, manipulating MS Word documents for accurately importing structured data would be very complex, if not impossible. We recommend that MS Word is not used for uploading data to SRDR.

\section{Time and Effort for Implementation}

As described in Appendix D, the process to import structured data into SRDR is a considerable improvement in the system's functionality. The time and effort required from EPCs for implementation of the approaches are minimal (i.e., testing each approach and the developed instructions took less than 1 hour).

\section{Data Rights, Section 508 Compliance, and Interoperability}

The process we have described in this project for improving how data can be imported into SRDR from MS Excel and DistillerSR did not involve any changes to the structure or layout of 
SRDR. As such, no consequent problems related to data rights, Section 508 compliance, and interoperability have been introduced.

\section{Conclusions}

In summary, in Aim 1, we surveyed Project Leads of recent EPC projects to determine what sources were being used for developing flat files for submission to SRDR. MS Excel and DistillerSR were the most frequent sources. In Aim 2, we developed and pilot tested approaches for importing data from MS Excel and from DistillerSR into SRDR. We hope that this work improves the ease with which structured data can be imported into SRDR. Next steps include further refinement of these approaches and evaluation of their utility to EPC Program. 


\section{References}

1. Ip S, Hadar N, Keefe S, et al. A Web-based archive of systematic review data. Syst Rev. 2012 Feb 21;1:15. doi: 10.1186/2046-4053-1-15. PMID: 22588052. 


\section{Appendix A. Survey Instrument Administered Through Qualtrics $^{\circledR}$}

When completing this survey, please consider the specific EPC project that we named in our email.

Please enter your first and last name.

Q1. What software tool or program did you primarily use when extracting data from studies for your review? (Select one)

- We did not use a software tool or program/we used paper and pencil or

- pen.

- DistillerSR

- REDcap

- Covidence

- Microsoft Access

- Microsoft Excel

- Microsoft Word

- Other, please specify:

Q2. What specific features/aspects of < software tool/program named in Q1> made you choose it for data extraction? (Please be as honest and specific as possible.)

Q3. What software tool or program did you primarily use when managing your extracted data and/or producing tables? (Select one)

- We did not use a software tool or program/we used paper and pencil or

- pen.

- DistillerSR

- REDcap

- Covidence

- Microsoft Access

- Microsoft Excel

- Microsoft Word

- Other, please specify:

Q4. Why did you not use SRDR for your review?

(Select all that apply. Please be honest because it will help improve SRDR. Responses will be analyzed in aggregate. If you have additional concerns about SRDR, we would love to hear from you and discuss them further. Please reach out to us at SRDR@AHRQ.HHS.gov.)

- The question types in SRDR were not flexible enough.

- The process of importing citations into SRDR was too cumbersome.

- The learning curve for using SRDR was too steep. 
- The data adjudication tool was not available.

- Exporting data was too slow.

- The format of the data exported from SRDR was not useful.

- The SRDR tool generally ran too slowly.

- The available formats and/or processes for importing data

- (retrospectively) were too limited.

- Abstract screening was not available in SRDR.

- It was unclear how to get support if needed.

- There were delays in getting support when needed.

- SRDR did not have certain features that we wanted. Please specify those

- features:

- There were other reasons. Please specify those reasons: 


\section{Appendix B. Screenshot of the MS Excel File Template}

for Importing Data Into the SRDR Design Tab

\begin{tabular}{|c|c|c|c|c|c|c|c|c|c|c|c|c|c|}
\hline$\Delta$ & A & B & c & D & E & $\mathrm{F}$ & G & H & 1 & J & $\mathrm{k}$ & L & M \\
\hline 1 & $\begin{array}{l}\text { Pubmed ID } \\
\text { (Only rqeuired if you do } \\
\text { not have PubMed ID or } \\
\text { Title and Author Info) }\end{array}$ & $\begin{array}{l}\text { Internal ID } \\
\text { (Only required if you do } \\
\text { not have PubMed ID or } \\
\text { Title and Author Info) }\end{array}$ & $\begin{array}{l}\text { Title } \\
\text { (Only required if you do not have PubMed ID } \\
\text { or Title and Author Info) }\end{array}$ & $\begin{array}{l}\text { Author } \\
\text { (Only required if you } \\
\text { use Title column) }\end{array}$ & $\begin{array}{l}\text { Year } \\
\text { (Optional) }\end{array}$ & $\begin{array}{l}\text { Journal } \\
\text { (Optional) }\end{array}$ & $\begin{array}{l}\text { Volume } \\
\text { (Optional) }\end{array}$ & $\begin{array}{l}\text { Issue } \\
\text { (Optional) }\end{array}$ & $\begin{array}{l}\text { Key } \\
\text { Question } \\
\text { (Optional) }\end{array}$ & Study Design & Sample Size & $\begin{array}{l}\text { Clinical } \\
\text { Setting }\end{array}$ & Country \\
\hline 2 & 23812661 & & $\begin{array}{l}\text { Comparative efficacy of LEAP, TEACCH and } \\
\text { non-model-specific special education } \\
\text { programs for preschoolers with autism } \\
\text { spectrum disorders }\end{array}$ & Boyd & & & & & & cohort & 10 & Hospital & India \\
\hline 3 & 25234481 & & $\begin{array}{l}\text { Measuring and Supporting Language } \\
\text { Function for Children with Autism: Evidence } \\
\text { from a Randomized Control Trial of a Social- } \\
\text { Interaction-Based Therapy }\end{array}$ & Casenhiser & & & & & & cas-control & 12 & $\begin{array}{l}\text { Community } \\
\text { center }\end{array}$ & US \\
\hline 4 & & & & & & & & & & & & & \\
\hline 5 & & & & & & & & & & & & & \\
\hline 6 & & & & & & & & & & & & & \\
\hline 7 & & & & & & & & & & & & & \\
\hline 8 & & & & & & & & & & & & & \\
\hline 9 & & & & & & & & & & & & & \\
\hline 10 & & & & & & & & & & & & & \\
\hline 11 & & & & & & & & & & & & & \\
\hline 12 & & & & & & & & & & & & & \\
\hline 13 & & & & & & & & & & & & & \\
\hline 14 & & & & & & & & & & & & & \\
\hline 15 & & & & & & & & & & & & & \\
\hline 16 & & & & & & & & & & & & & \\
\hline
\end{tabular}


Appendix C. Screenshot of the MS Excel File Template for Importing Data Into the SRDR Outcomes Tab

\begin{tabular}{|c|c|c|c|c|c|c|c|c|c|c|c|c|c|c|c|c|c|}
\hline 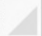 & A & B & c & D & E & $\mathrm{F}$ & G & H & 1 & J & $\mathrm{k}$ & L & M & $\mathrm{N}$ & 0 & P & Q \\
\hline 1 & $\begin{array}{l}\text { Pubmed ID } \\
\text { (Only } \\
\text { rqeuired if } \\
\text { you do not } \\
\text { have } \\
\text { PubMed ID } \\
\text { or Title and } \\
\text { Author Info) }\end{array}$ & $\begin{array}{l}\text { Internal ID } \\
\text { (Only } \\
\text { required if } \\
\text { you do not } \\
\text { have } \\
\text { PubMed ID } \\
\text { or Title and } \\
\text { Author Info) }\end{array}$ & $\begin{array}{l}\text { Title } \\
\text { (Only } \\
\text { required if } \\
\text { you do not } \\
\text { have } \\
\text { PubMed ID } \\
\text { or Title and } \\
\text { Author Info) }\end{array}$ & $\begin{array}{l}\text { Author } \\
\text { (Only } \\
\text { required if } \\
\text { you use } \\
\text { Title } \\
\text { column) }\end{array}$ & $\begin{array}{l}\text { Year } \\
\text { (Optional) }\end{array}$ & $\begin{array}{l}\text { Journal } \\
\text { (Optional) }\end{array}$ & $\begin{array}{l}\text { Volume } \\
\text { (Optional) }\end{array}$ & $\begin{array}{l}\text { Issue } \\
\text { (Optional) }\end{array}$ & $\begin{array}{l}\text { Key } \\
\text { Question } \\
\text { (Optional) }\end{array}$ & $\begin{array}{l}\text { Outcome } \\
\text { (Required) }\end{array}$ & $\begin{array}{l}\text { Outcome } \\
\text { Description } \\
\text { (Required) }\end{array}$ & $\begin{array}{l}\text { Type } \\
\text { (Reqired, } \\
\text { Must use } \\
\text { values: } \\
\text { Continuous, } \\
\text { Categorical, } \\
\text { or Time to } \\
\text { Event) }\end{array}$ & $\begin{array}{l}\text { Timepoints } \\
\text { (Optional) }\end{array}$ & $\begin{array}{l}\text { Timepoint } \\
\text { Units } \\
\text { (Optional) }\end{array}$ & $\begin{array}{l}\text { Subgroups } \\
\text { (Optional) }\end{array}$ & $\begin{array}{l}\text { Subgroup } \\
\text { Description } \\
\text { (Optional) }\end{array}$ & \\
\hline 2 & & 23 & & & & & & & & Symptom & Symptom seve & Time to Event & & & & & \\
\hline 3 & & 23 & & & & & & & & Fibroid volume $f$ & fibroid volume & Continuous & & year & & & \\
\hline 4 & & 23 & & & & & & & & Fibroid volume & fibroid volume & Continuous & & year & & & \\
\hline 5 & & 23 & & & & & & & & Subsequent tre: & HIFU, new & Categorical & BL & NA & & & \\
\hline 6 & & 23 & & & & & & & & Subsequent tre: & HIFU, new & Categorical & EOT & NA & & & \\
\hline 7 & & 23 & & & & & & & & Subsequent tre: & HIFU, new & Categorical & LFU & NA & & & \\
\hline 8 & & & & & & & & & & & & & & & & & \\
\hline 9 & & & & & & & & & & & & & & & & & \\
\hline 10 & & & & & & & & & & & & & & & & & \\
\hline 11 & & & & & & & & & & & & & & & & & \\
\hline 12 & & & & & & & & & & & & & & & & & \\
\hline 13 & & & & & & & & & & & & & & & & & \\
\hline 14 & & & & & & & & & & & & & & & & & \\
\hline 15 & & & & & & & & & & & & & & & & & \\
\hline 16 & & & & & & & & & & & & & & & & & \\
\hline 17 & & & & & & & & & & & & & & & & & \\
\hline
\end{tabular}




\section{Appendix D. Instructions for Importing Structured Data From DistillerSR Into SRDR}

\section{Introduction}

The purpose of this document is to provide step-by-step instructions for the process of importing structured data from DistillerSR into the Systematic Review Data Repository (SRDR). Note that this feature is only available in the newest version of SRDR, i.e., SRDR+. However, for simplicity purposes and to be consistent with the rest of this report, this Appendix uses the term SRDR.

There are three main steps to the process of importing structured data from DistillerSR into SRDR. These steps assume that the user has access to the relevant project in DistillerSR. However, if the user does not have access to Distiller, simply having access to the Section files is sufficient, in which case, the user should proceed directly to Step 3.

The steps described in this document are intended to apply to the end of the process of data extraction in a systematic review, once the data are already extracted in DistillerSR. Currently, once the data are imported into SRDR, we have not yet developed interoperability in the opposite direction (i.e., importing of data extracted in SRDR into DistillerSR).

\section{Clarification of Terms}

Before we proceed with describing the steps involved with the importing process, we provide below some explanations/definitions of terms:

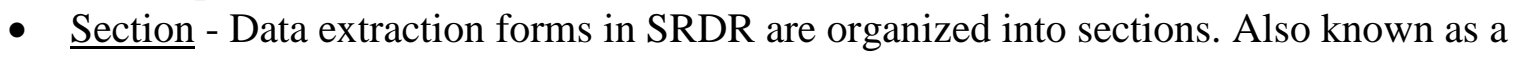
$t a b$, each section refers to a collection of questions/items in the data extraction form.

- Section File - This is a file that is exported from DistillerSR that will ultimately be imported into a corresponding section in SRDR.

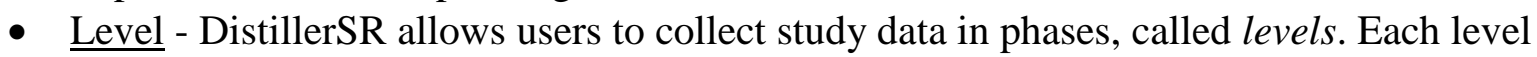
either contains a form to be filled, or multiple sub-levels. When importing into SRDR, each level is mapped to an extraction form section.

\section{Limitations of Current Importing Options}

One limitation with current importing options is related to differences in how DistillerSR and SRDR collect and store systematic review data. For example, SRDR projects contain structured elements such as outcomes, populations, and comparisons that have no counterpart in DistillerSR. This incompatibility makes it difficult to create a fully formed SRDR project by interpreting data exports out of DistillerSR. Instead, when importing data, SRDR creates a barebones version of the project that contains none of the structured element, such as outcomes or comparisons. Rather, SRDR imports each DistillerSR file into a separate data extraction form section, where the data contained in the file are represented as question-answer pairs. The names of the imported extraction form sections are the choice of the user importing the project.

It should also be noted that once a project is imported, additional DistillerSR files cannot be imported subsequently into the same project. Therefore, we strongly recommend that the user export all the data out of DistillerSR and only then begin the import process into SRDR. 


\section{Steps of Importing Structured Data From DistillerSR Into SRDR}

\section{Step 1 of 3 - Exporting a File Containing Study References From DistillerSR}

1. Go to the DistillerSR home page.

2. Log into your account.

3. Use the dropdown at the top of the page to select the project to be exported.

4. In the top bar, click on Datarama (Figure D-1).

Figure D-1. Distiller SR home page

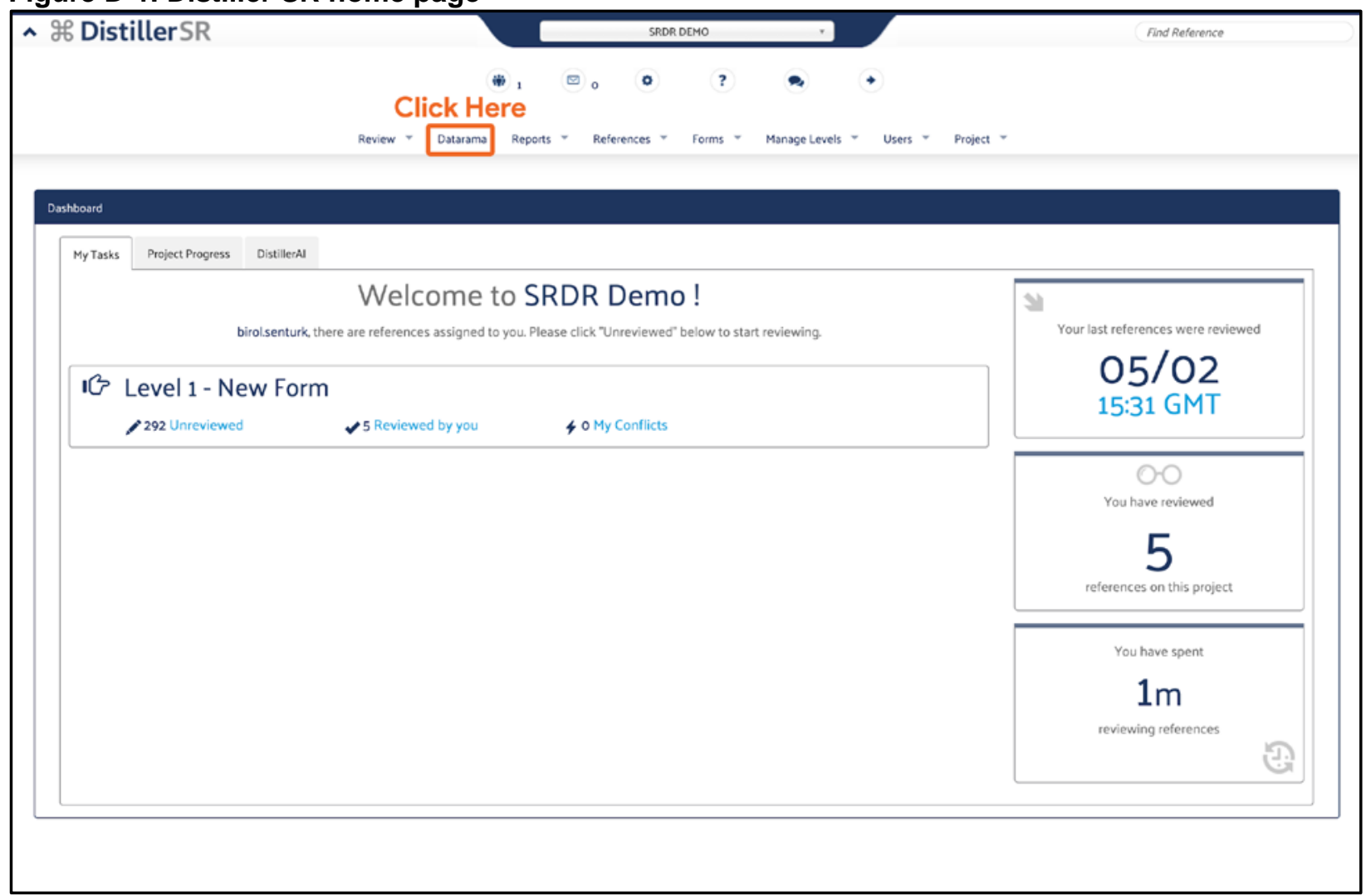

5. Click on the Report Settings Tab:

a. Under the Basic Options panel (Figure ii):

i. From the Report Format dropdown, select the RIS option.

ii. This step is optional - Enter a filename for the export into the textbox labeled Export File name (optional).

b. Under the Data to Display panel (Figure D-2):

i. Ensure that none of the checkboxes are checked.

c. Click on the Reference Display Options Tab and under the Reference Fields panel:

i. Ensure that all checkboxes are selected (Figure D-3).

6. Click on Run Report at the bottom left of the page to start the export. 
Figure D-2. "Report Settings" tab of the Datarama page

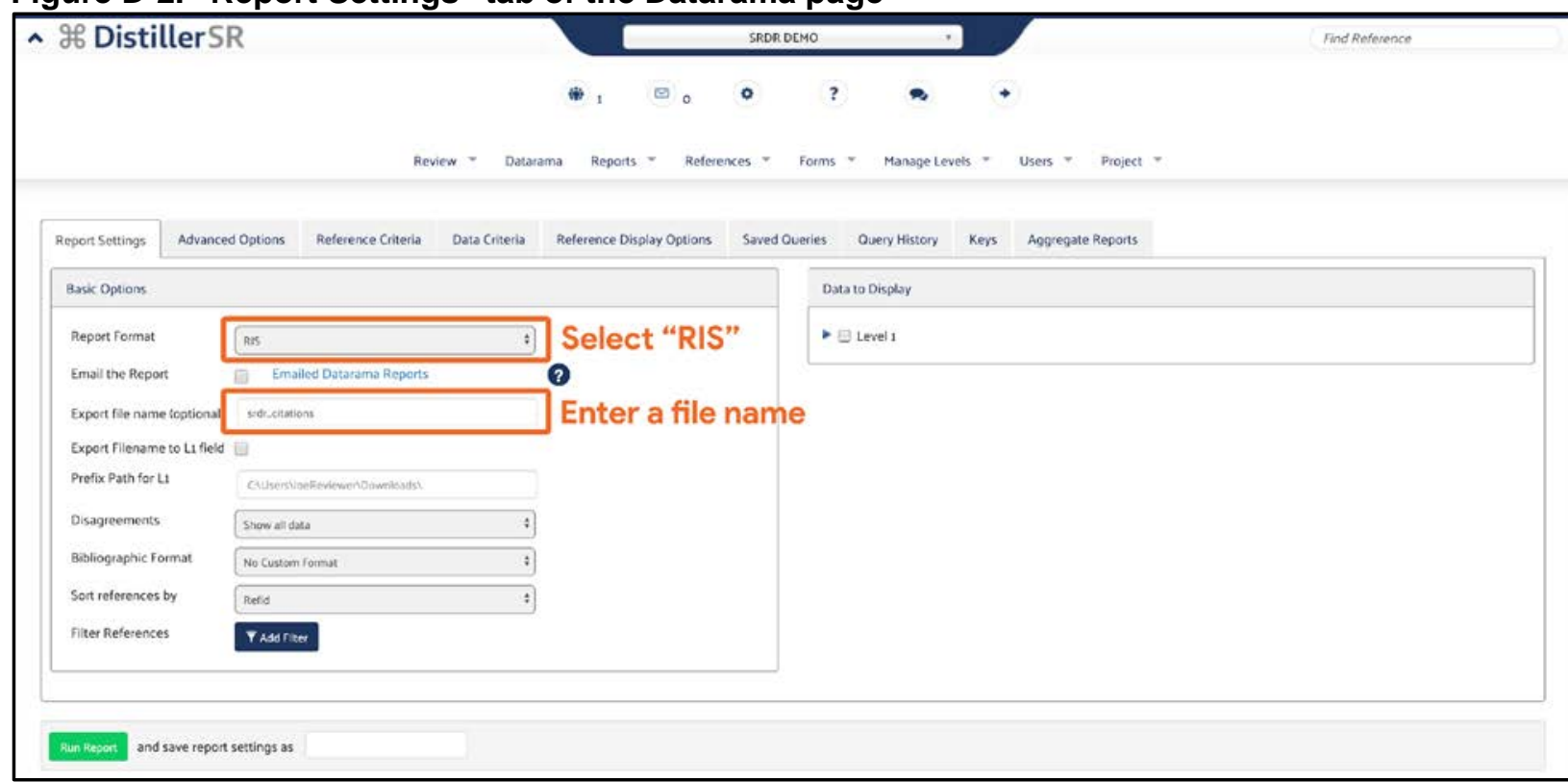

Figure D-3. "Reference Display Options" tab of the Datarama page

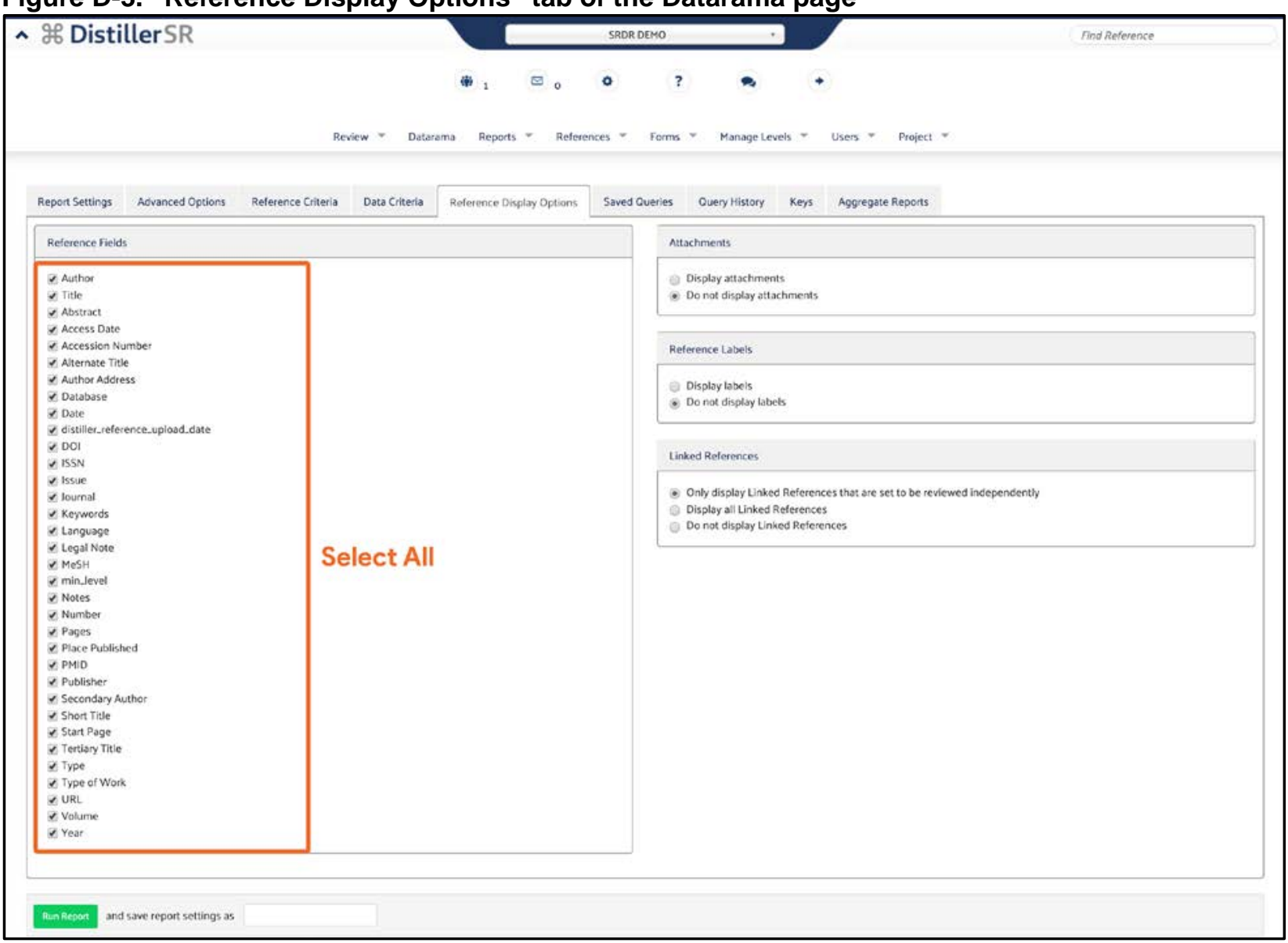




\section{Step 2 of 3 - Exporting Section File(s) From DistillerSR}

1. Go to the DistillerSR Home Page.

2. Log into your account.

3. Use the dropdown at the top of the page to select the project to be exported.

4. In the top bar, click on Datarama.

5. Go to the Report Settings Tab:

a. Under the Basic Options panel (Figure D-4):

i. From the Report Format dropdown, select the CSV option.

ii. Enter a filename for the export into the textbox labeled Export File name(optional). This step is optional.

b. Under the Data to Display panel (Figure D-4):

i. Click on the checkbox next to the level you want to export.

ii. Ensure that only one checkbox is selected.

Figure D-4. "Report Settings" tab of the "Datarama" page

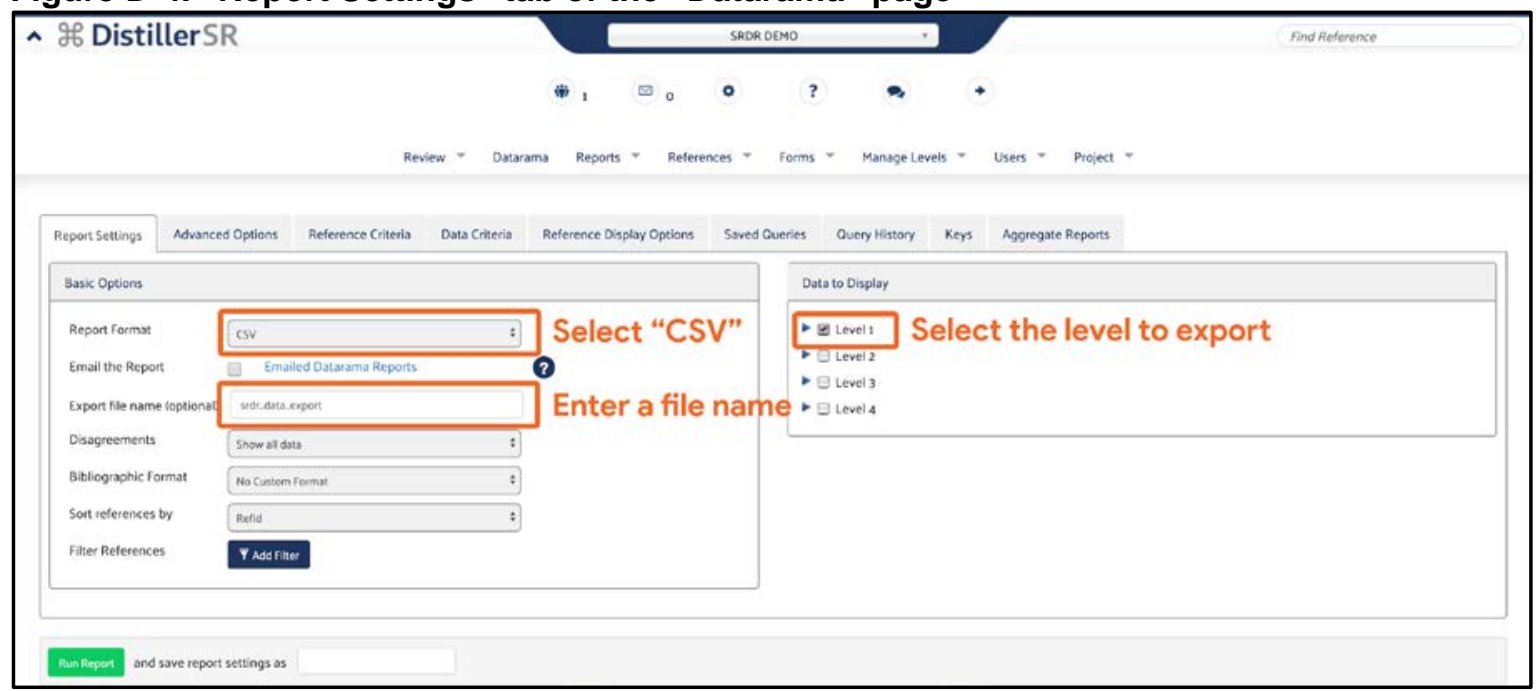

6. Go to Advanced Options Tab:

a. Under the Advanced Options panel (Figure D-5):

i. Click on the checkbox labeled Merge Sets by Key.

ii. Click on the checkbox labeled Show RefIDs of linked references.

iii. Ensure that none of the other checkboxes are checked. 
Figure D-5. "Advanced Options" tab of the Datarama page

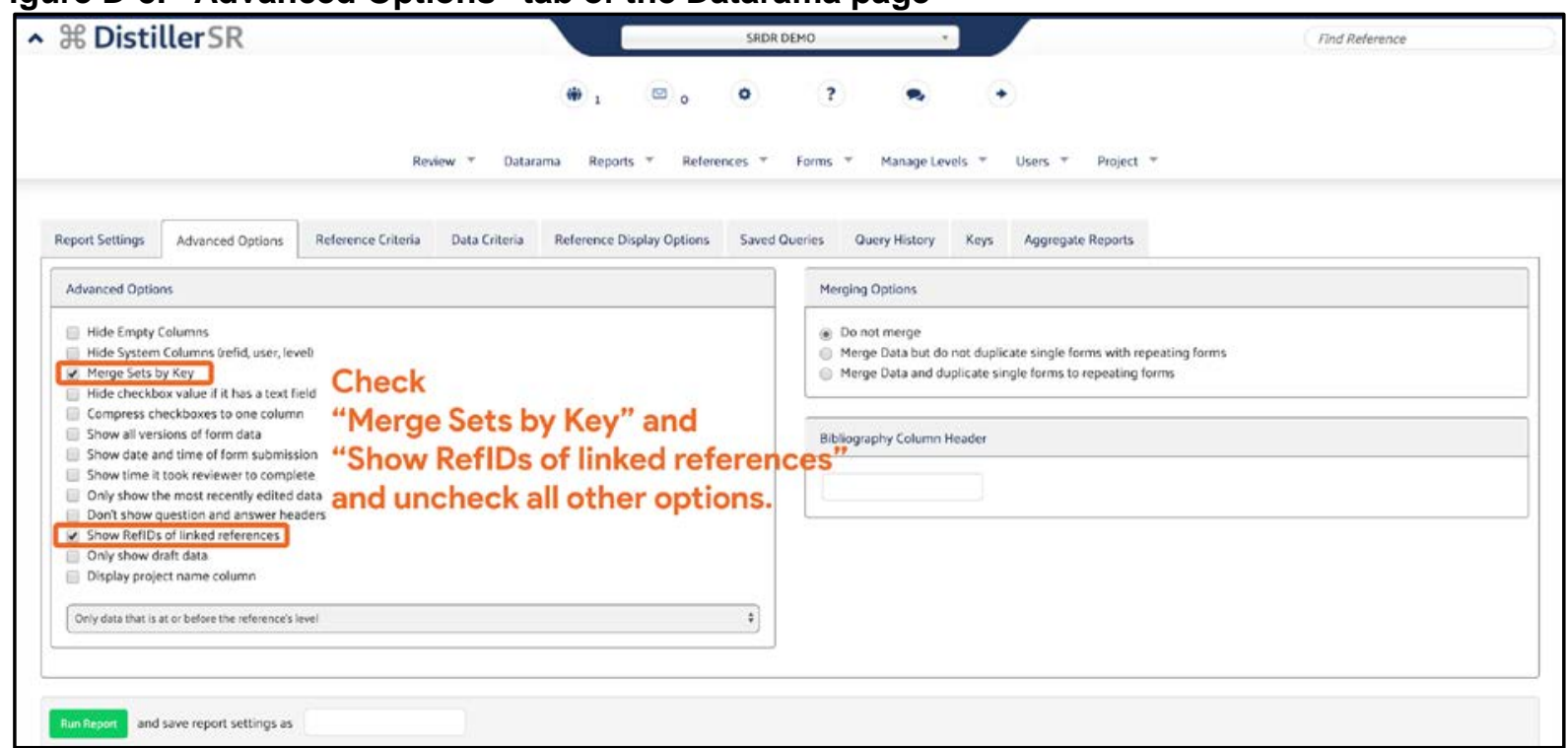

7. Click on Run Report at the bottom left of the page to start the export.

8. Repeat steps 1 through 8 until all the desired levels are exported as section files.

\section{$\underline{\text { Step } 3 \text { of } 3}$ - Importing the References File and Section File(s) into SRDR}

1. Go to the SRDR Home Page (https://srdrplus.ahrq.gov).

2. Log into your account.

3. Click on Dashboard at the top bar.

4. Click on Create Project at the top right (Figure D-6).

Figure D-6. Portion of the "Dashboard" page showing Create Project button

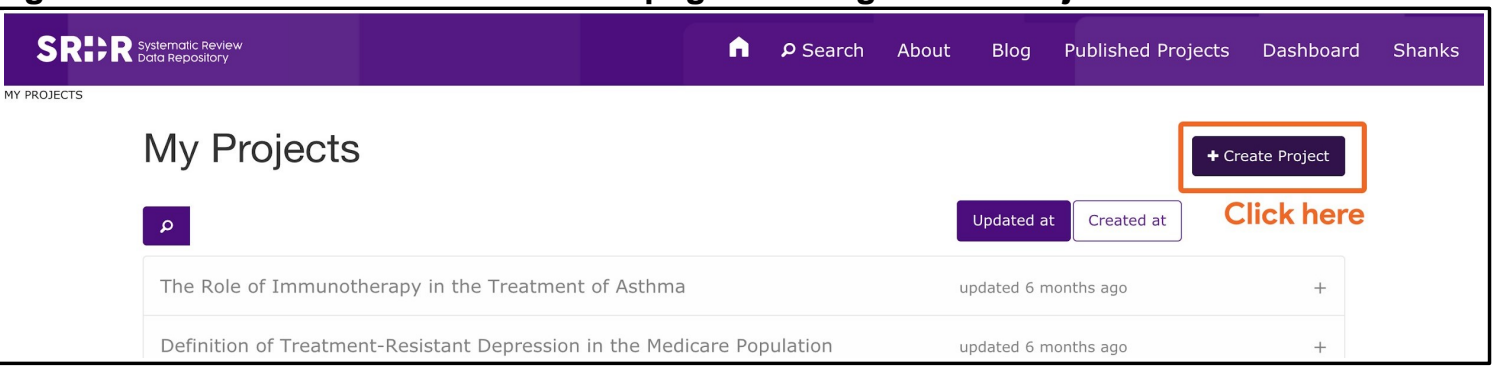

5. Enter a name for the imported project using the textbox labeled Name.

6. This step is optional - Enter a description for the imported project using the textbox labeled Description.

7. Click on the dropdown that says Create an empty project and then select the option to “Create a project from a Distiller SR .csv export” (Figure D-7). 
Figure D-7. Portion of the "+ Create Project" page with "create an empty project" dropdown

Start a new Project

* Name

Distiller Import Test

Description

Back

Select

Create an empty project

"Create project from a

Create Project

Distiller SR .csv export"

from the dropdown.

8. Under the Distiller References File panel (Figure D-8):

a. Click on Choose File, then select the References File exported from DistillerSR.

b. Ensure that selected File Type is .ris.

Figure D-8. Portion of the "+ Create Project" page with "References File" panel

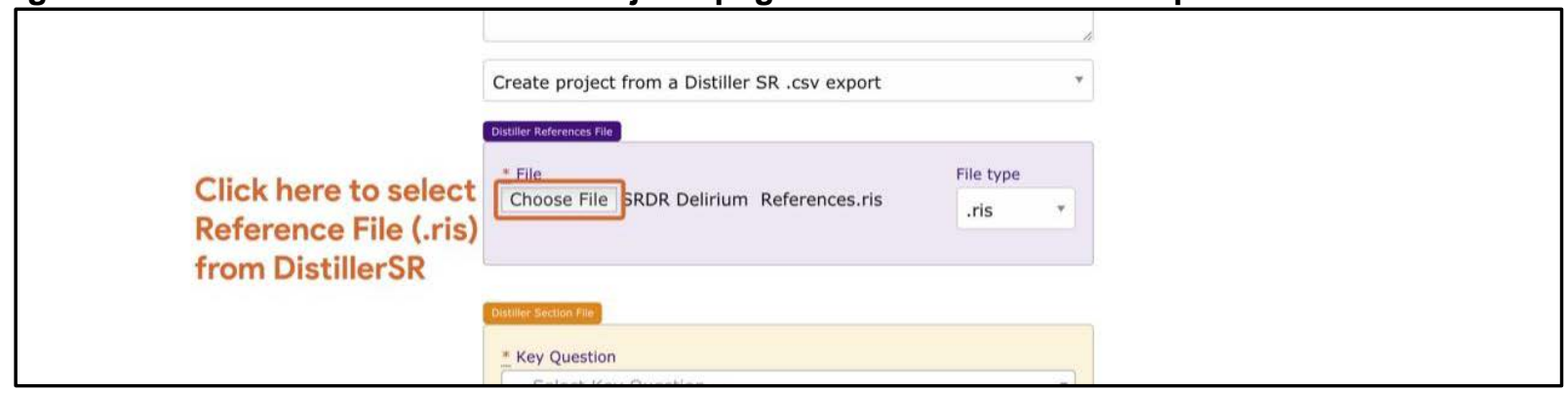

9. Under the Distiller Section File panel:

a. Click on the Choose File button (or Browse... button on Firefox), and then select a Section File exported from DistillerSR (Figure D-9).

Figure D-9. Portion of the "+ Create Project" page with "Choose File" button

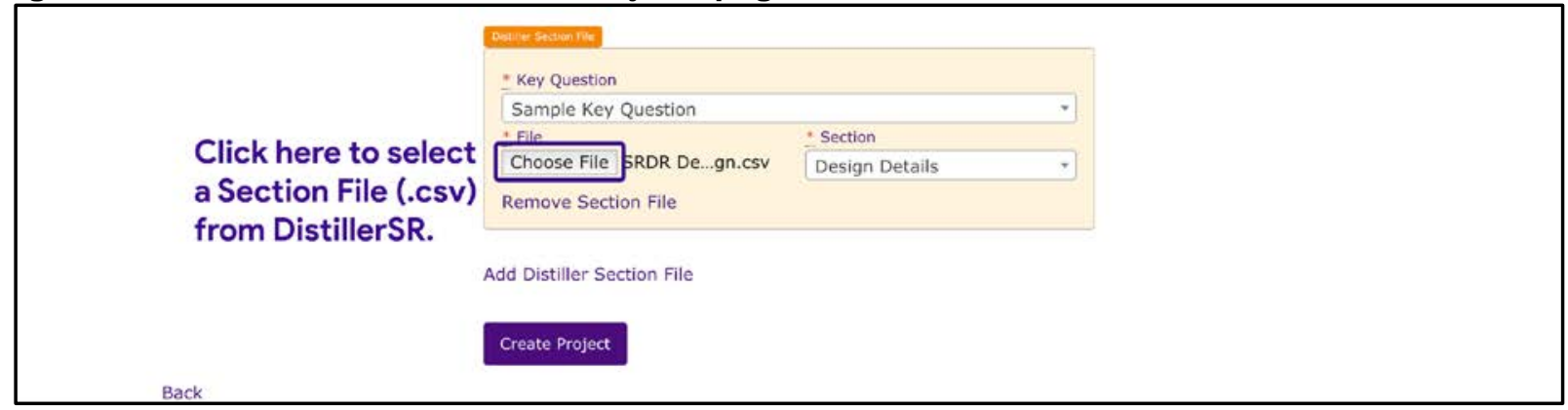

b. Click on the dropdown labeled Key Question and type in the key question addressed by the Section File (Figures D-10 and D-11).You can also select from the previously entered key questions by clicking on the dropdown option. 
Figure D-10. Portion of the "+ Create Project" page with "Key Question" dropdown

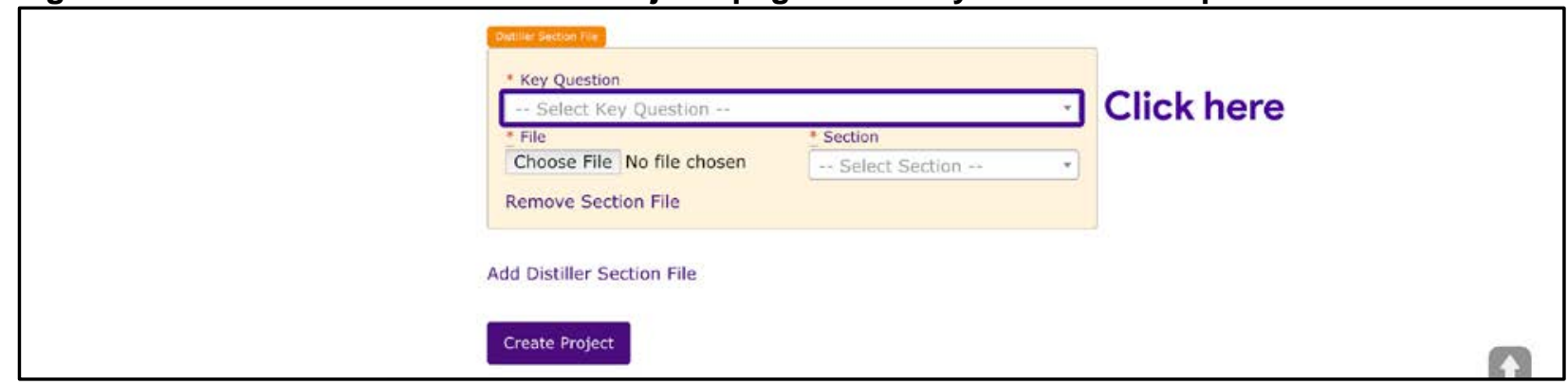

Figure D-11. Portion of the "+ Create Project" page with "Key Question" box

\begin{tabular}{|l|l|}
\hline Sample Key Question & Type in a Key Question \\
\hline A sample key question & and press Enter \\
Sample Key Question & (or select from dropdown) \\
Add Distiller Section File &
\end{tabular}

c. Click on the dropdown labeled Section and type in a name for the extraction form section (Figure D-12 and D-13). You can also select from the defaults by clicking on the dropdown option.

Figure D-12. Portion of the "+ Create Project" page with "Section" dropdown

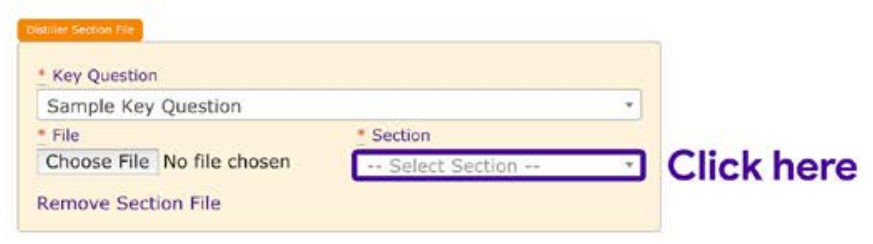

Add Distiller Section File

Create Project

Figure D-13. Portion of the "+ Create Project" page with section name box

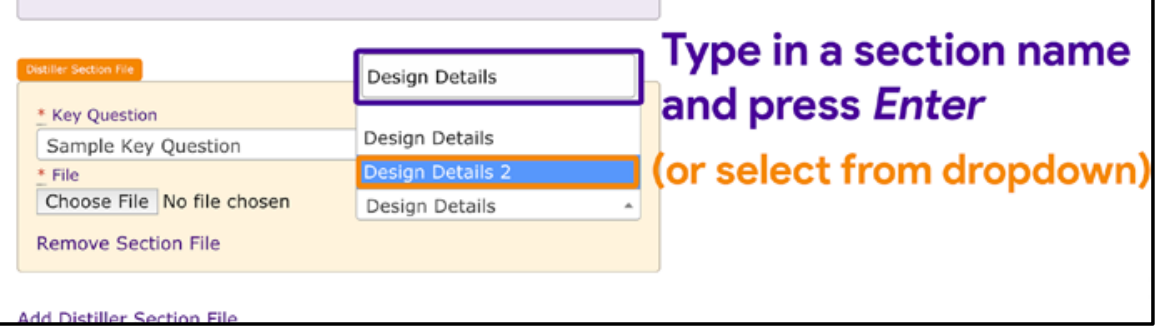

10. If there are additional Section Files to import, click on the Add Distiller Section File link and repeat Step 7 (Figure D-14). 
Figure D-14. Portion of the "+ Create Project" page with "Add Distiller Section File" link

\begin{tabular}{|l|l|}
\hline Choose File SRDR De...gn.csv Design Details \\
Remove Section File \\
Add Distiller Section File (you can click here to add more sections) \\
Create Project
\end{tabular}

11. Click on Create Project to start the import (Figure D-15). A green notification will appear indicating that the import is being processed (Figure D-16).

Figure D-15. Portion of the "+ Create Project" page with "Create Project" button

Add Distiller Section File

Create Project Lastly, click here to start importing.

Back

Figure D-16. Portion of the "Edit Project" page with green notification

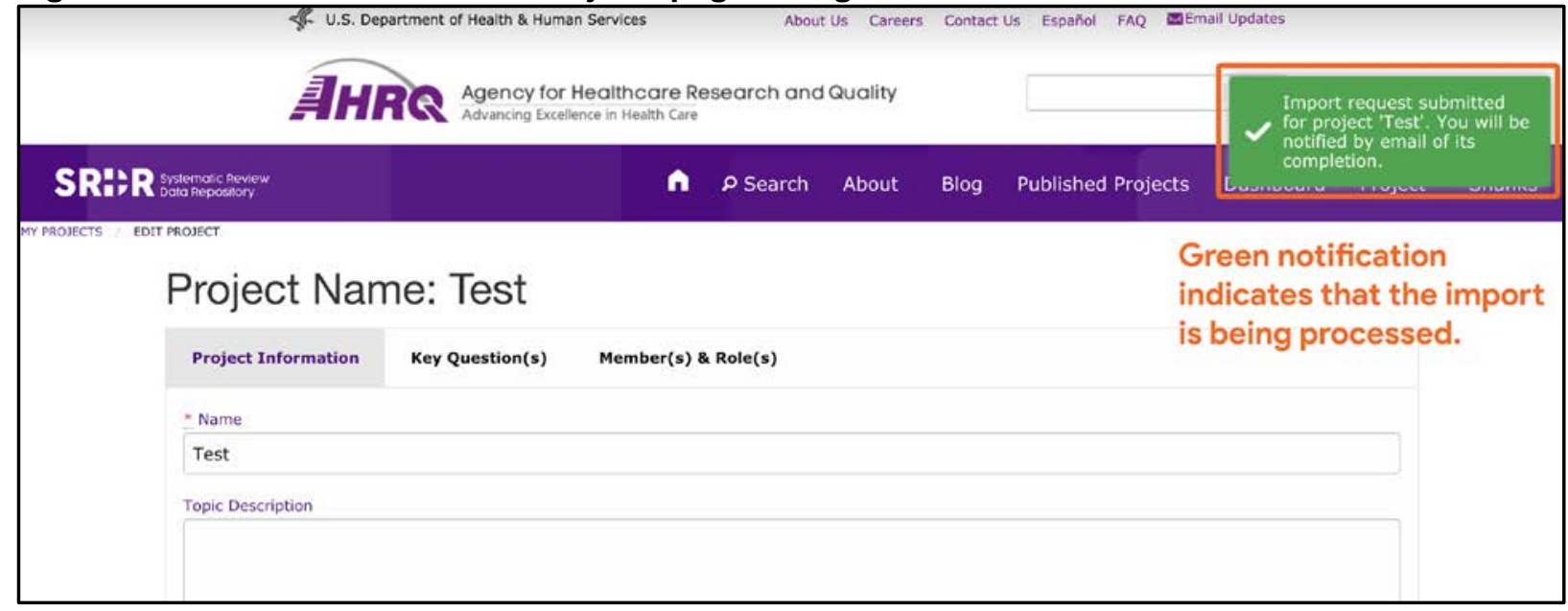

